\title{
Nota Científica / Short Communication Vanilla appendiculata (Orchidaceae): primeiro registro para o estado do Mato Grosso, Brasil
}

\author{
Vanilla appendiculata (Orchidaceae): first record to Mato Grosso State, Brazil
}

\author{
Mathias Erich Engels ${ }^{1,3}$ \& Lilien Cristhiane Ferneda Rocha ${ }^{2}$
}

\begin{abstract}
Resumo
É apresentado o primeiro registro de Vanilla appendiculata para o estado do Mato Grosso, sendo este o limite sul de distribuição da espécie. São apresentadas a descrição, comentários taxonômicos e ecológicos, mapa de localização, e uma prancha fotográfica da espécie estudada.

Palavras-chave: baunilha, epífita, neotrópico, nova ocorrência, orquídea.

Abstract

The first record of Vanilla appendiculata for the state of Mato Grosso is presented, which is also the first record of the species outside the Northern Brazilian region. The description, taxonomic and ecological comments, and a photo of the studied species are presented.
\end{abstract}

Key words: vanille, epiphyte, neotropics, new record, orchid.

Vanilla Mill. é um gênero de Orchidaceae Juss. constituído predominantemente por ervas hemiepífitas lianescentes, com cerca de 110 espécies e distribuição pantropical (Govaerts 2015). Ocorrendo em todo o território brasileiro, esta representada por 34 espécies, com maior representatividade nas regiões Norte e Sudeste. No Estado do Mato Grosso, é citada a ocorrência de nove espécies: Vanilla chamissonis Klotzsch, V. eggersii Rolfe, $V$. ensifolia Rolfe, $V$. lindmaniana Kraenzl., $V$. mexicana Mill., V. palmarum (Salzm. ex Lindl.) Lindl., $V$. planifolia Jacks. ex Andrews, $V$. pompona Schiede e $V$. ribeiroi Hoehne (BFG 2015).

Vanilla appendiculata era conhecida apenas para a região Norte do Brasil, nos estados do Acre, Amazonas, Pará e Roraima (BFG 2015) e para a Guiana, Suriname e Peru (Govaets 2015). Sendo aqui acrescentado o novo registro para o estado do Mato Grosso, que corresponde ao limite austral da distribuição geográfica desta espécie.

\section{Material e Métodos}

Durante o subprograma de resgate de Flora da Usina Hidrelétrica de Colíder foram coletadas amostras de $V$. appendiculata. Estas foram herborizadas seguindo as técnicas usuais da taxonomia vegetal (Fidalgo \& Bononi 1989) e estão depositadas no herbário MBM, acrônimo de acordo com Thiers (continuamente atualizado). Os nomes válidos e sinônimos foram adotados de acordo com Govaerts (2015).

\section{Taxonomia}

Vanilla appendiculata Rolfe, Bull. Misc. Inform. Kew 1895: 178. 1895.

= Vanilla marowynensis Pulle, Enum. Vasc. P1. Surinam: 118. 1906.

= Vanilla purusara Barb.Rodr. ex Hoehne, Arq. Bot. estado São Paulo, n.s., f.m., 1: 127. 1944.

Fig. 1

Erva hemiepífita, escandente. Raízes 0,2 $\mathrm{cm}$ espessura, cilíndricas, castanho-alvacentas. Caule 0,7 cm espessura, cilíndrico, escandente, verde; entrenós 2,6-7,5 cm comp. Folhas 13-19

\footnotetext{
Assessoria Técnica Ambiental Ltda., R. Marechal José Bernardino Bormann 821, 80730-350, Batel, Curitiba, PR, Brasil.

Juris Ambientis Consultores S S Ltda., R. Humberto Costa 96, 80040-150, Hugo Lange, Curitiba, PR, Brasil.

Autor para correspondência: mathiasengels@hotmail.com
} 

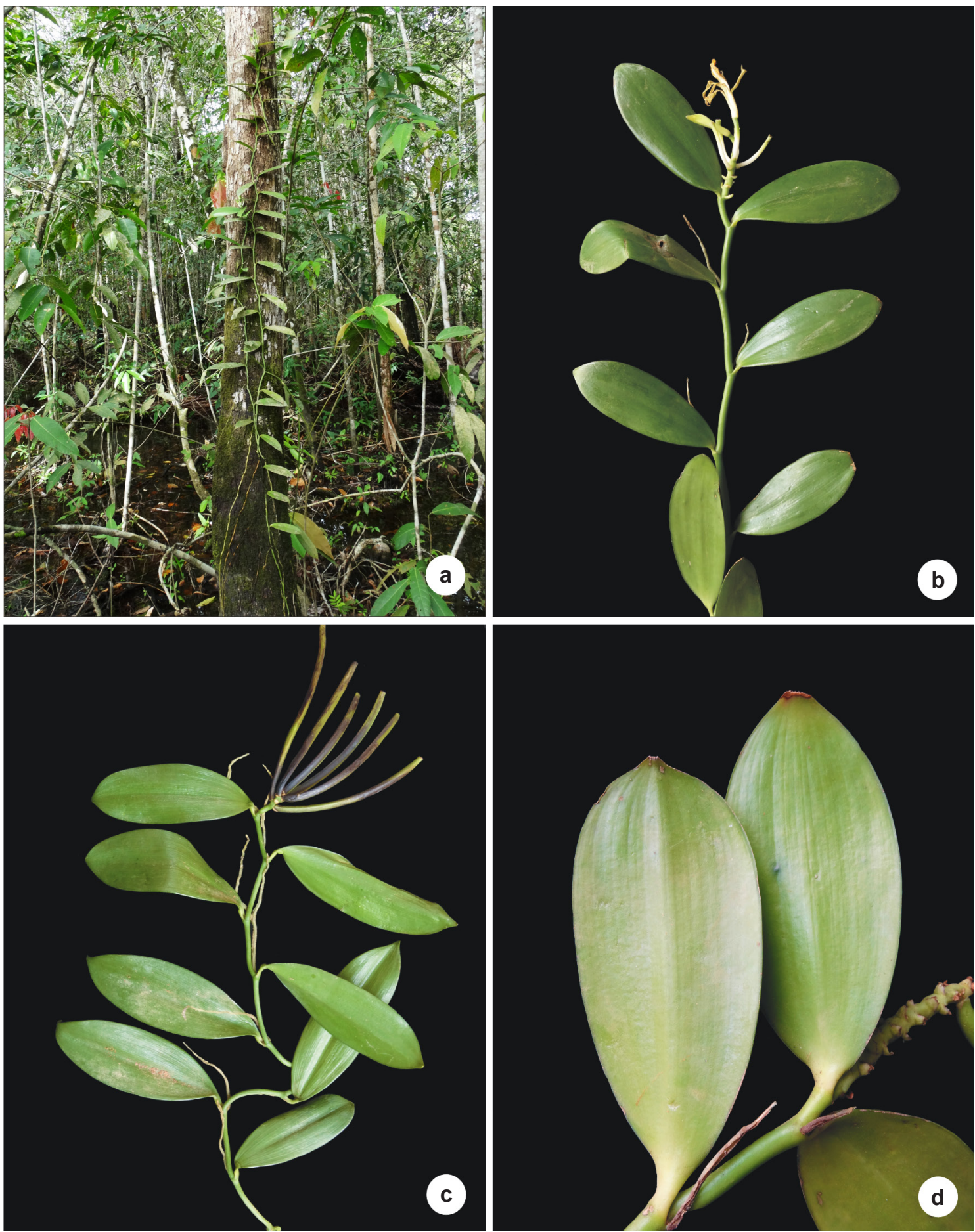

Figura 1 - Vanilla appendiculata Rolfe - a. hábito; b. ramo em floração; c. ramos em frutificação; d. detalhe das folhas. Figure 1 - Vanilla appendiculata Rolfe - a. habit; b. flowering branche; c. fruiting branches; d. detail of the leaves. 
$\times$ 3,9-5,7 cm, planas, obovoides, cartáceas a levemente carnosas, base aguda, margem lisa, ápice cuspidado. Inflorescência 3-10 × 0,5-0,6 $\mathrm{cm}$, racemosa, apical, multiflora. Flor com ovário e pedicelo 2,5-4 ×0,4 cm, cilíndrico, base alva e ápice verde; sépala dorsal $6,6 \times 0,7 \mathrm{~cm}$, linearlanceolada, base oblonga, margem lisa, ápice agudo, amarelo esverdeada; sépalas laterais $6,6 \times 0,7 \mathrm{~cm}$, linear-lanceolada, base oblonga, margem lisa, ápice agudo, amarelo esverdeadas; pétalas $6,5 \times 0,6 \mathrm{~cm}$, linear-lanceoladas, base oblonga, margem lisa, ápice agudo, amarelo esverdeadas; labelo $6,8 \times 1,6 \mathrm{~cm}$, parcialmente adnato à coluna, obovado, base aguda, margem crespa, ápice cuspidado e densamente fimbriado, amarelo; fimbrias 0,2 cm comp., lineares; calos 2, no centro da labelo, obdeltoides, ápice truncado e piloso. Coluna $5,4 \times 0,2 \mathrm{~cm}$, levemente achatada dorsoventralmente. Antera $0,3 \times 0,2 \mathrm{~cm}$. Fruto $10-17,4 \times 0,5-1 \mathrm{~cm}$, cápsula não totalmente seca, cilíndrica, deiscência basípeta, verde e castanho. Sementes negras.

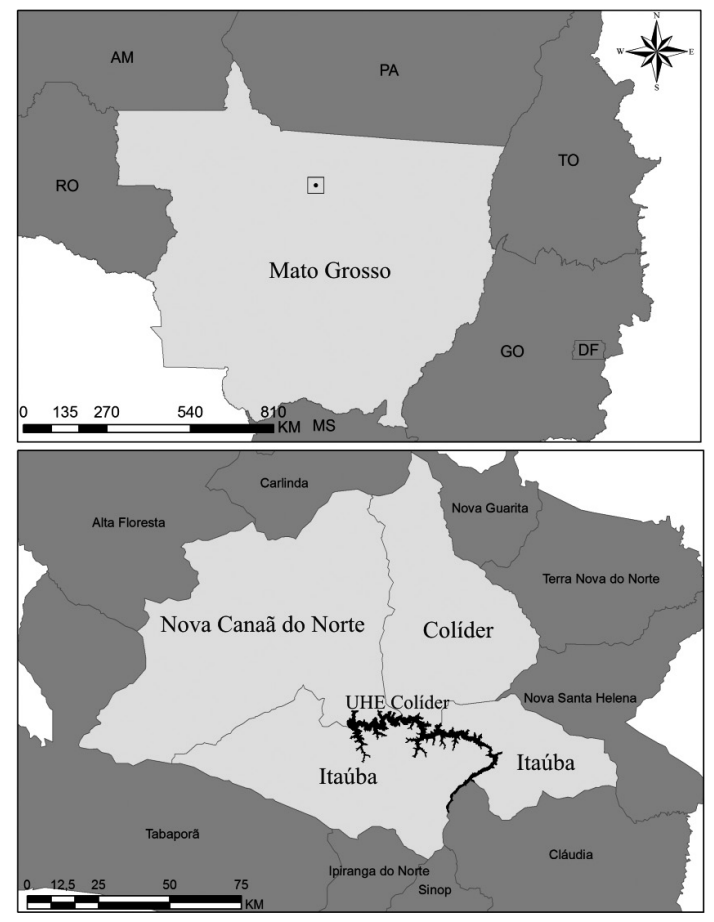

Figura 2 - Mapa de localização dos municípios matogrossenses onde ocorre Vanilla appendiculata Rolfe.

Figure 2 - Location map of Mato Grosso municipalities where it occurs Vanilla appendiculata Rolfe.
Material examinado: Colíder, Resgate de Flora da UHE Colíder, Lote B de supressão, 16.VIII.2014, fl., M.E. Engels 2583 (MBM); Itaúba, Resgate de Flora da UHE Colíder, Lote C de supressão, 15.IX.2014, fr., M.E. Engels 2738 (MBM); Nova Canaã do Norte, Resgate de Flora da UHE Colíder, Lote A de supressão, 15.VIII.2014, fr., M.E. Engels 2739 (MBM).

Vanilla appendiculata ocorre como hemiepífita nas florestas às margens do rio Teles Pires, na região Centro Norte do Mato Grosso (Fig. 2), área de ecótono entre os domínios Amazônico e Cerrado. Foi encontrada vegetando em áreas sombreadas e úmidas, numa altura de cerca de 2 até 5 metros, nunca ultrapassando o estrato médio. Apresentando-se normalmente como indivíduos solitários, raramente formando touceiras, e neste caso não muito densas.

Esta espécie foi tratada por Hoehne (1945), na Flora Brasílica, por seu sinônimo V. purusara Barb.Rodr. ex Hoehne, onde foi descrita e bem ilustrada (táb. $n^{\circ}$ 21). Ainda, de acordo com Hoehne, esta espécie impressiona pela forma das folhas e do labelo. As folhas obovoides e o labelo obovado com ápice cuspidado densamente fimbriado distinguem $V$. appendiculata das demais espécies do gênero que ocorrem no estado do Mato Grosso. O fruto maduro possui deiscência basípeta, que ocorre gradativamente com a desidratação. Possui fraco odor adocicado, semelhante à baunilha.

Este primeiro registro de Vanilla appendiculata fora da região Norte do Brasil, no Estado do Mato Grosso, contribui com a ampliação do conhecimento da flora do estado e da espécie estudada.

\section{Agradecimentos}

À Companhia Paranaense de Energia Elétrica (COPEL), a autorização da publicação dos dados aqui contidos. Ao consorcio CIA Ambiental e seus colaboradores. À Renata C. Barreto por ajudar na confecção do mapa.

\section{Referências}

BFG. 2015. Growing knowledge: an overview of Seed Plant diversity in Brazil. Rodriguésia 66: 1085-1113. Fidalgo, O. \& Bononi, V.L.R. 1989. Técnicas de coleta, preservação e herborização de material botânico. Reimpressão. Instituto de Botânica, São Paulo. 62p.

Govaerts, R. 2014. World checklist of Orchidaceae. Facilitated by the Royal Botanic Gardens, Kew. Disponível em <http://www.kew.org/wcsp/ monocots $>$. Acesso em 26 abril 2015. 
Hoehne, F.C. 1945. Orchidaceas. In: Hoehne, F.C. Flora brasílica 8 , v. 12, parte II. Graficars-F. Lanzara, São Paulo. 389p.
Thiers, B. [continuously updated]. Index Herbariorum: The Herbaria of the world. Disponível em $<\mathrm{http} / /$ sweetgum.nybg.org/ih/>. Acesso em 17 agosto 2014. 